DOI: $10.5216 /$ cab.v13i4.17173

\title{
RESISTÊNCIA DO LIGAMENTO DA CABEÇA DO OSSO FEMORAL EM CÃES
}

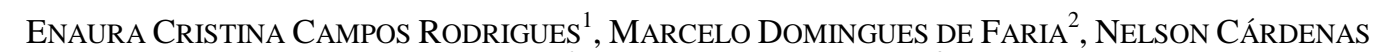 \\ OLIVIER $^{2}$, JOAQUIM PEREIRA NETO 3
}
${ }^{1}$ Graduanda da Fundação Universidade Federal do Vale do São Francisco, Petrolina, PE, Brasil. - enaura_cris_@hotmail.com
${ }^{2}$ Professores Doutores da Fundação Universidade Federal do Vale do São Francisco, Petrolina, PE, Brasil.
${ }^{3}$ Professor Mestre da Universidade do estado da Bahia, Juazeiro, BA, Brasil.

\begin{abstract}
Com o número crescente de animais de companhia nos lares, o aumento de sua longevidade e, em muitos casos, a forma errônea de criá-los, aumentam, concomitantemente, diversas afecções, como as patologias articulares, gerando a demanda de estudos voltados às mesmas. O objetivo deste trabalho foi determinar a capacidade máxima de resistência do ligamento da cabeça do osso femoral em cães até sua ruptura, estabelecendo correlações entre cargas exercidas $(\mathrm{kg})$, deslocamento das garras de extensão $(\mathrm{mm})$ e variação do tempo (s) por meio de instrumentação eletrônica que proporciona mensuração de forças e controle do deslocamento. Foram utilizados 42 cães adultos, sem raça definida, com massa corporal variando entre 4,5 e $26 \mathrm{~kg}$, eutanasiados pelo Centro de Controle de Zoonoses de Petrolina (PE). Inicialmente, promoveu-se somatometria, isolou-se a pelve dos animais, rebatendo estruturas adjacentes, evidenciando a articulação coxal. As peças foram divididas em dois

hemicoxais, o osso femoral, fraturado no terço médio e a cápsula articular, rebatida para visualizar o ligamento da cabeça do osso femoral, que foi submetida ao ensaio mecânico destrutivo. Dos animais estudados, 08 apresentaram resistência óssea menor que a resistência ligamentosa, gerando fratura da cabeça do osso femoral em pelo menos um antímero. As dimensões e massa corpórea do indivíduo interferiram na resistência do ligamento da cabeça do osso femoral. Nas fêmeas, o ligamento estudado apresentou resistência de $22 \mathrm{~kg} \pm$ $8,55 \mathrm{~kg}$ no antímero direito e $21,18 \mathrm{~kg} \pm 8,45 \mathrm{~kg}$, no esquerdo. Nos machos foi de $21,76 \mathrm{~kg} \pm 9, \mathrm{~kg}$ no antímero direito e $23,55 \mathrm{~kg} \pm 9,06 \mathrm{~kg}$, no esquerdo. Este trabalho foi alvitrado com o propósito de gerar subsídio técnicocientífico aos profissionais que atuam nas diversas áreas da medicina veterinária e engenharia médica para desenvolvimento de tecnologias na elaboração de materiais que sejam substitutivos dos tecidos naturais.
\end{abstract}

PALAVRAS-CHAVE: Canis familiaris; ligamento da cabeça do osso femoral; resistência.

\section{RESISTENCE OF THE FEMORAL HEAD LIGAMENT IN DOGS}

\section{ABSTRACT}

The growing number of pets, as well as the increase of their life expectancy and, in many cases, the wrong way to raise them have led to a concurrent increase of a variety of diseases, such as joint pathologies, which demand studies. The aim of this study was to determine the maximum strength of the dog's ligament of the femoral bone head until its rupture, in order to establish correlations between charges carried $(\mathrm{kg})$, displacement of the extension grip $(\mathrm{mm})$, and variation of the time (s) by means of electronic instrumentation systems that provide measurement of forces and displacement control. We used 42 mongreel adult dogs with body mass from 4.5 to $26 \mathrm{~kg}$. Initially, we performed biometry, and then the animal's pelvis was isolated, removing adjacent structures, exposing coxal joint. The pieces were divided into two hemicoxals, the femur was fractured in the middle, and the joint capsule withdrawn to show the ligament of the the femoral bone head, which underwent destructive 
mechanical testing. From the animals studied, eight showed less bone strength than ligamentous resistance, generating fractured femoral head at least on one side. The dimensions and body mass of the individual interfered in the resistance of the ligament of the femoral bone head. In females, the ligament showed resistance of $22 \mathrm{~kg} \pm 8.55$ on the right antimere, and $21.18 \mathrm{~kg} \pm 8.45 \mathrm{~kg}$ on the left. In males it was $21.76 \mathrm{~kg} \pm 9.3 \mathrm{~kg}$ on the right antimere, and $23.55 \mathrm{~kg} \pm 9.06 \mathrm{~kg}$ on the left. The main purpose of this study was to provide technical and scientific information to professionals who work in different areas of veterinary medicine and medical engineering to develop technologies for the elaboration of materials that are substitutes for natural tissues.

KEYWORDS: Canis familiaris; Ligamenta capitis ossis femoris; resistance.

\section{INTRODUÇÃO}

Segundo FARIA (2007), devido à falta de alimentos em diversos locais no período de escassez de chuvas, determinados animais selvagens aproximavam-se dos seres humanos, fator que determinou o início da domesticação de cães. No Egito antigo, esse animal foi bastante utilizado pelo homem tanto na caça quanto como animal de companhia, além de protegê-los de inimigos e animais agressores.

Com base no que foi citado acima, afirma-se que a domesticação trouxe benefícios tanto para o homem quanto para o cão. A partir de então, uma forte aliança foi firmada entre essas espécies, na qual o homem era o líder e o cão, exímio caçador que, com o passar do tempo, assimilou os costumes concernentes à sociedade humana (FARIA, 2007).

Com a evolução da domesticação, a relação homem-animal estreitou-se, contribuindo para o aumento do numero de cães incorporados à família. Devido a essa aproximação, cresceu a preocupação com a higidez de seus animais, prolongando a sua longevidade, o que gerou maior número de patologias, dentre elas, as articulares.

Anteriormente chamada de articulação coxofemoral, por envolver os ossos relacionados, a articulação coxal é assim denominada, visto que envolve ossos da coxa e do quadril, através do acetábulo e da cabeça do osso femoral (NOMINA ANATOMICA VETERINARIA, 2005). É bastante resistente e constituída por várias estruturas como: cápsula articular, acetábulo (confluência do ílio, ísquio e púbis), um ligamento extrínseco denominado ligamento transverso do acetábulo e um ligamento intrínseco, o ligamento da cabeça do osso femoral.

Segundo DYCE et al. (2004), a articulação coxal apresenta extensa amplitude no cão, visto que possui grande potencial de abdução, permitida através da anatomia da cabeça do osso femoral, que é um hemisfério perfeito, porém prejudicado pela fóvea, onde se inserem os ligamentos intrínsecos ou intracapsulares, os quais possuem comprimento e espessura variáveis, embora suficientemente frouxos para subsistirem impactos.

Existe uma série de afecções ortopédicas causadas pela combinação de fatores como hereditariedade, dieta alimentar, atividade física e manejo. A displasia coxofemural é o exemplo mais comumente encontrado em cães na clínica médica, sendo um distúrbio degenerativo, progressivo e irreversível, constituindo grave problema, porque estão associadas a osteoartrite coxofemoral, mobilidade/amplitude limitada da articulação, dor e claudicação em graus variáveis. Em cães, é um processo doloroso porque o desgaste articular expõe as fibras álgicas no osso subcondral (LEMOS, 2007).

Com a preocupação de desenvolver técnicas e tecidos que possam substituir o tecido lesionado ou degenerado, alguns trabalhos de pesquisa vêm procurando determinar a resistência dos ligamentos articulares. A resistência dos materiais é um ramo da mecânica que estuda as relações entre cargas externas aplicadas a um corpo deformável e a intensidade das forças internas que atuam dentro do corpo (HIBBELER, 2004). A resistência de tecidos orgânicos é um ramo pouco estudado tanto na medicina humana quanto na medicina veterinária. Assim, os referenciais bibliográficos disponíveis são bastante escassos. Dessa forma, o principal objetivo deste trabalho foi determinar a resistência do ligamento da cabeça do osso femoral, procurando estabelecer possíveis correlações existentes com a biometria corporal ou com o gênero sexual.

\section{MATERIAL E MÉTODOS}

O presente trabalho foi devidamente certificado pelo Comitê de Ética no Uso de Animais da Universidade Federal do Vale do São Francisco com protocolo $\mathrm{n}^{\circ} 045240409$.

Para a realização deste estudo, foram utilizados 19 cães do sexo masculino e 23 cães do sexo feminino, adultos de porte médio e diferentes idades, sem raça definida, provenientes do Centro de Controle de Zoonoses (CCZ) do Município de Petrolina, devidamente eutanasiados. 
Para a determinação da biometria corporal, foram utilizados fita métrica e paquímetro de aproximação em milímetros, com o intuito de obterse:

- altura: determinada por meio da aferição das extremidades distal dos membros torácicos à região do ombro, compreendida entre os processos espinhosos das vértebras torácicas, localizada entre as escápulas, zootecnicamente denominada de cernelha;

- comprimento: conferido por meio do intervalo compreendido ao longo da coluna vertebral, entre a crista nucal e a inserção da cauda;

- cintura escapular (largura): determinada tomando-se a medida entre as espinhas escapulares contra-laterais;

- cintura pélvica (largura): determinada tomandose a medida compreendida entre as tuberosidades coxais das asas ilíacas;

- altura do tórax: conferida tomando-se as medidas compreendidas entre a base do esterno e os processos espinhosos da sétima ou oitava vértebras torácicas;

- altura do abdome: conferida por meio da aferição realizada entre a cicatriz umbilical e os processos espinhosos da terceira ou quarta vértebras lombares;

- comprimento da cabeça: determinado pelo intervalo compreendido entre a sutura frontonasal e a crista nucal;

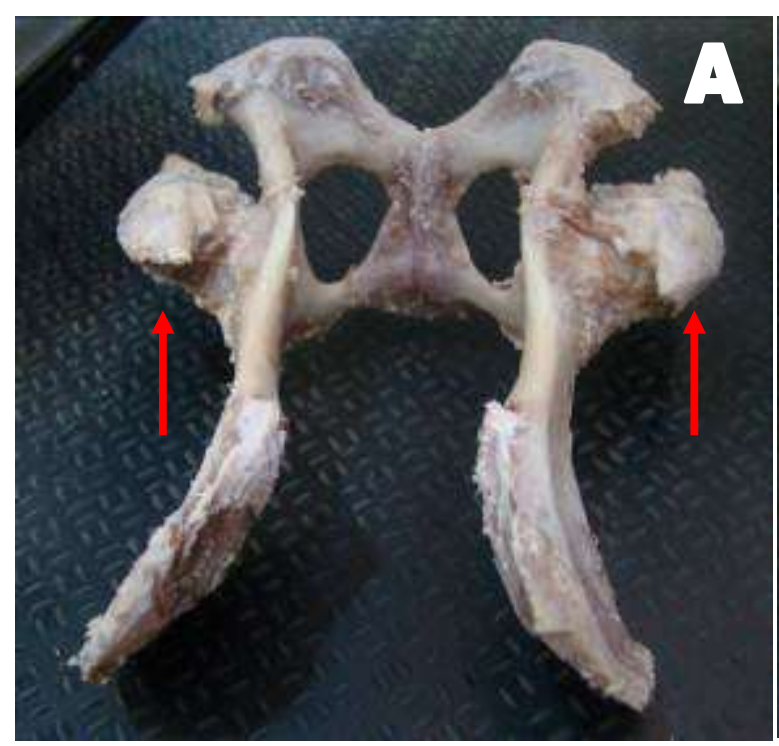

- comprimento da face: obtido por meio do intervalo compreendido entre o ápice do nariz e a sutura fronto-nasal;

- largura da cabeça: conferida por meio da aferição do espaço compreendido entre as faces laterais dos arcos zigomáticos contra-laterais;

- altura da cabeça: determinada por meio do intervalo compreendido entre a crista nucal e o ângulo da mandíbula.

Utilizando-se balança analítica digital (Techline $\left.{ }^{\circledR}\right)$, foi determinada a massa corporal dos animais, expressa em quilogramas.

Após a eutanásia, os animais foram conduzidos ao Laboratório de Anatomia dos Animais Domésticos e Silvestres do Campus de Ciências Agrárias da Universidade Federal do Vale do São Francisco, situado no Município de Petrolina, Estado de Pernambuco (latitude 09 $23^{\prime} 55 \mathrm{~S}$, longitude $40^{\circ} 30^{\prime} 03 \mathrm{~W}$ e altitude de $376 \mathrm{~m}$ ).

Como foram estudados 42 animais, foram analisadas 84 articulações coxais, as quais foram obtidas através do rebatimento dos músculos extrínsecos e intrínsecos da pelve, músculos perineais, músculos lombares e abdominais e músculos da coxa, além de outras estruturas de sustentação da pelve, como ligamentos, vasos e nervos, e de seus órgãos internos.

Após a obtenção do osso coxal na sua integridade, o osso femoral foi fraturado no terço médio com auxílio de serra fita (FIGURA 1).

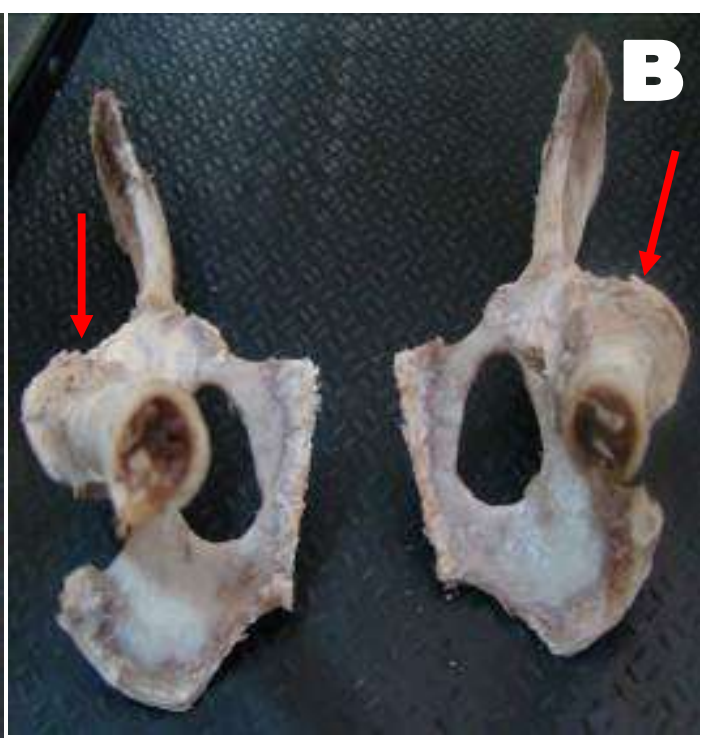

Figura 1 - Na fotografia A, os hemicoxais estão unidos pela sínfise púbica. Já na fotografia B, o osso coxal foi fraturado sobre a sínfise púbica. Nas setas, estão evidenciadas as epífises proximais dos ossos femorais UNIVASF, Petrolina, 2010.

A cápsula articular foi rebatida para o acesso ao ligamento da cabeça do osso femoral (FIGURA 
2). Posteriormente, os hemi-coxais foram separados por meio de fratura na sínfise púbica (FIGURA 1), com auxílio de serra fita e costótomo.

Para a realização do ensaio mecânico destrutivo, foram usadas máquinas universais de ensaios DL (Digital Line) da EMIC (FIGURA 3). Seu sistema de instrumentação eletrônica é dotado de canais de medição de forças (para células de carga) e deformação (para extensômetros) com fatias de velocidade da travessa móvel variando de 0,01 $\mathrm{mm} / \mathrm{min}$ a $1000 \mathrm{~mm} / \mathrm{min}$, proporcionando controle e precisão nos deslocamentos. À garra superior da máquina foi fixado o hemi-coxal e à garra inferior, o terço proximal do osso femoral, aplicando-se uma força $(\mathrm{N})$ tal, que não induzia à fratura da estrutura óssea no ponto de fixação (FIGURA 3).

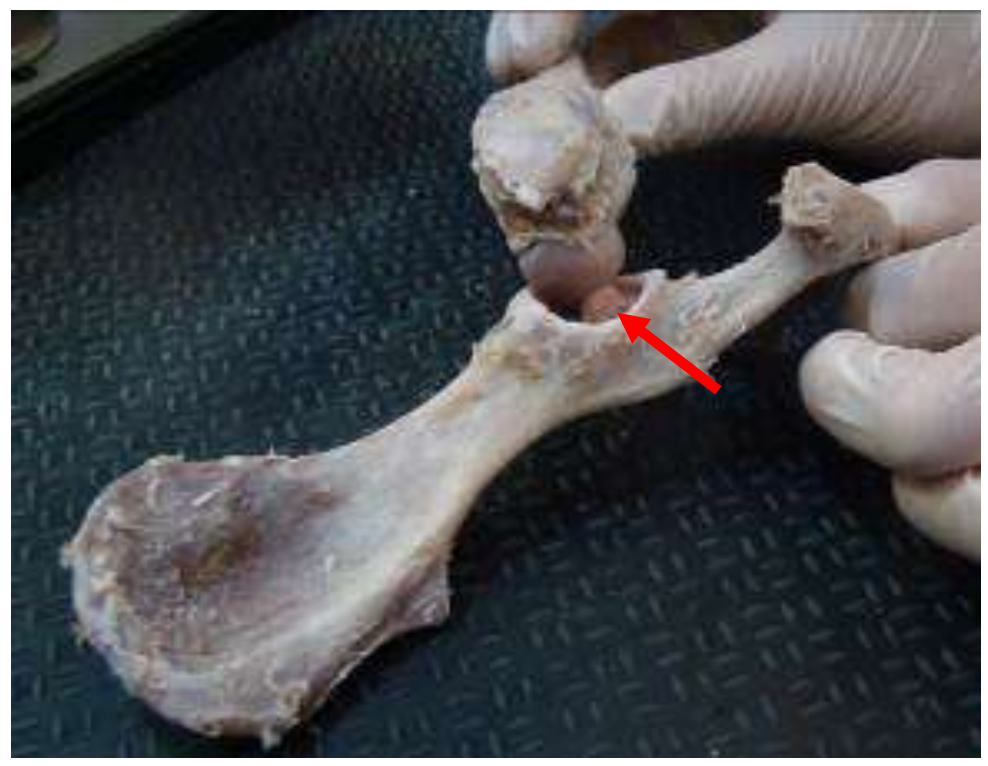

Figura 2 - Fotografia da articulação coxal evidenciando o ligamento da cabeça do osso femoral (seta vermelha) após rebatimento da cápsula articular - UNIVASF, Petrolina, 2010.
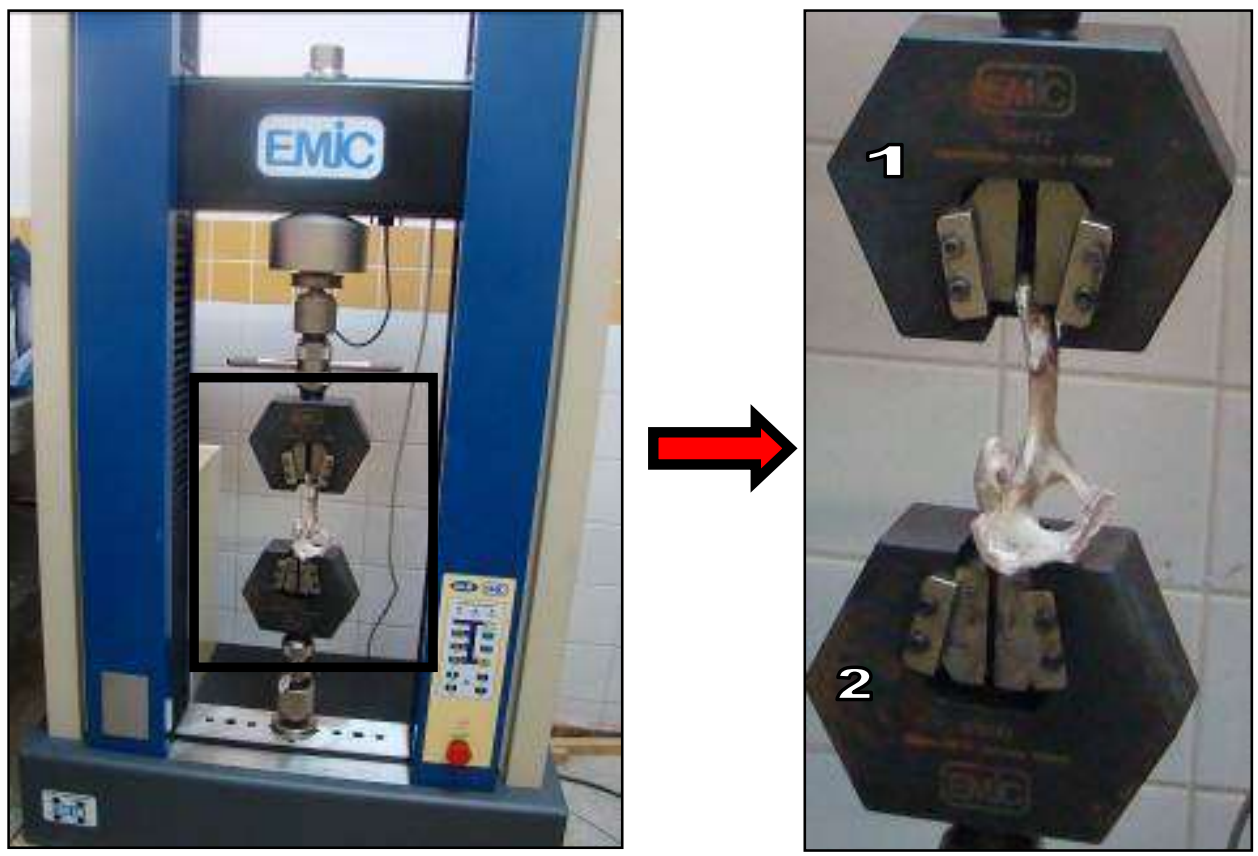

Figura 3 - Visualização da garra superior da máquina de ensaio mecânico destrutivo, fixa ao hemi-coxal e garra inferior, fixa ao terço proximal do osso femoral - UNIVASF, Petrolina, 2010. Legenda - 1 - Garra superior/ 2 - Garra inferior. 
O deslocamento em milímetros $(\mathrm{mm}) \mathrm{da}$ garra superior foi analisado, avaliando-se a deformação $(\mathrm{mm})$ do ligamento por unidade de tempo (s) e força $(\mathrm{N})$ em uma velocidade de 5 (cinco) milímetros $(\mathrm{mm})$ por segundo (s) até sua ruptura (FIGURA 4). Após a execução do ensaio mecânico da estrutura, os dados foram tabulados e gráficos de dispersão linear foram confeccionados com o intuito de estabelecer as devidas correlações (GRÁFICO 1).

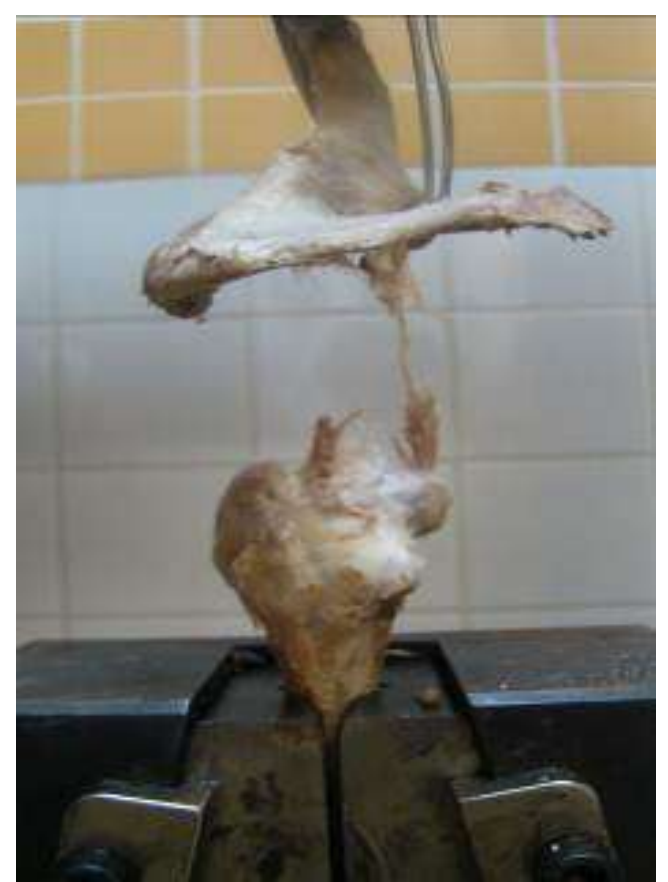

Figura 4 - Fotografia do momento de ruptura completa do ligamento da cabeça do osso femoral - UNIVASF, Petrolina, 2010.

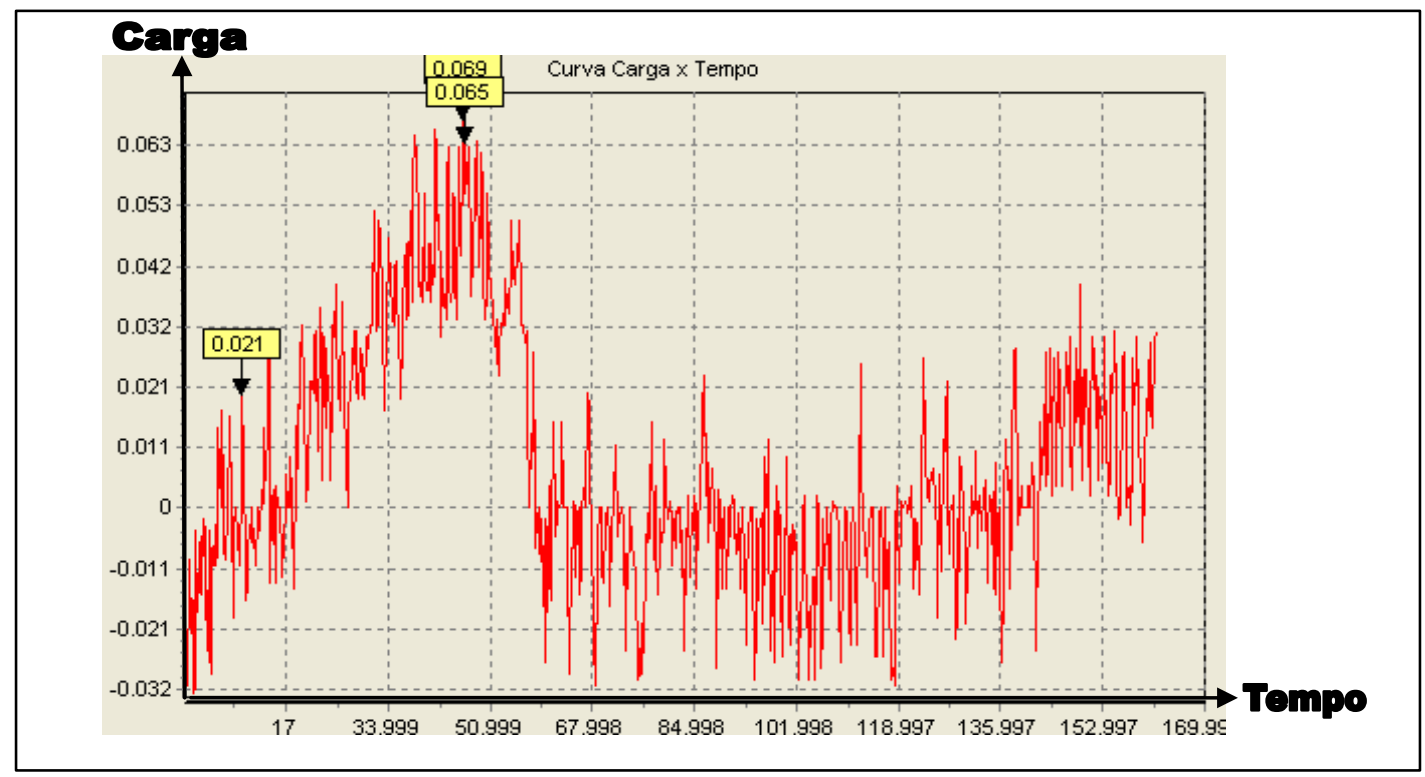

Gráfico 1 - Visualização de curva de correlação entre carga e tempo, obtida por meio de ensaio mecânico destrutivo - UNIVASF, Petrolina, 2010.

Para a realização das análises estatísticas, 2003), sendo o primeiro utilizado para testar foi utilizado o Programa $R$, que é um sistema a correlação entre as variáveis de machos e fêmeas desenvolvido a partir da linguagem $\mathrm{S}$, bem como o (com nível de significância menor que 0,05 e nível programa SAS (Statistic Analysis System, 2002- de correlação maior que 0,5) e o segundo, para 
promover a análise de variância e verificar as correlações existentes entre as variáveis estudadas, utilizando-se o Procedimento GLM.

\section{RESULTADOS E DISCUSSAO}

Dos 42 cães utilizados inicialmente, quatorze $(33,33 \%)$ apresentaram fratura no colo da cabeça do osso femoral em pelo menos um antímero, antes que houvesse a aplicação máxima de carga, a qual levaria à ruptura do ligamento da cabeça do osso femoral, ou seja, nesses animais, o referido ligamento apresentou resistência maior que a do próprio osso. Assim, no intuito de homogeneizar a amostra estudada, optou-se por utilizar apenas os outros vinte e oito cães (14 do gênero masculino e 14 do gênero feminino) para promover a análise estatística. De acordo com os métodos utilizados na análise estatística, não houve diferenças significativas entre machos e fêmeas; seus valores médios e desvios padrão seguem na Tabela 1.

Após submeter o ligamento da cabeça do osso femoral à ação de ensaio mecânico destrutivo, foi possível estabelecer sua resistência por intermédio da força máxima de ruptura, expressa em quilogramas, bem como o deslocamento, que é o afastamento entre a cabeça do osso femoral e a fossa do acetábulo, expresso em milímetros, demonstrados na Tabela 2.
Tabela $1-$ Médias e desvios-padrão das características corporais de cães utilizados para pesquisa de resistência do ligamento da cabeça do osso femoral - Petrolina, 2010

\begin{tabular}{l|cc|c|c}
\hline \multirow{2}{*}{ VARIÁVEL } & \multicolumn{2}{|c|}{ MÉDIA } & \multicolumn{2}{c}{$\begin{array}{c}\text { DESVIO- } \\
\text { PADRÃO }\end{array}$} \\
\cline { 2 - 5 } & Fêmea & Macho & Fêmea & Macho \\
\hline $\begin{array}{l}\text { Massa corporal } \\
\text { (kg) }\end{array}$ & 12,17 & 15,14 & 3,54 & 4,34 \\
$\begin{array}{l}\text { Altura corporal } \\
\text { (cm) }\end{array}$ & 47,23 & 47,23 & 5,74 & 5,74 \\
$\begin{array}{l}\text { Comprimento } \\
\text { corporal (cm) }\end{array}$ & 60,48 & 61,75 & 6,14 & 7,32 \\
$\begin{array}{l}\text { Cintura } \\
\text { escapular (cm) }\end{array}$ & 13,95 & 11,07 & 4,93 & 4,93 \\
$\begin{array}{l}\text { Cintura pélvica } \\
\text { (cm) }\end{array}$ & 11,09 & 11,53 & 2,83 & 2,30 \\
$\begin{array}{l}\text { Altura do tórax } \\
\text { (cm) }\end{array}$ & 24,90 & 26,99 & 3,32 & 2,90 \\
$\begin{array}{l}\text { Altura do } \\
\text { abdome (cm) }\end{array}$ & 22,98 & 23,37 & 3,54 & 3,60 \\
$\begin{array}{l}\text { Comprimento } \\
\text { da cabeça (cm) }\end{array}$ & 13,64 & 15,39 & 3,93 & 3,92 \\
$\begin{array}{l}\text { Comprimento } \\
\text { da face (cm) }\end{array}$ & 8,69 & 8,69 & 2,55 & 4,08 \\
$\begin{array}{l}\text { Largura da } \\
\text { cabeça (cm) }\end{array}$ & 14,40 & 14,33 & 1,87 & 2,09 \\
$\begin{array}{l}\text { Altura da } \\
\text { cabeça (cm) }\end{array}$ & 11,22 & 12,90 & 2,27 & 1,81 \\
\hline
\end{tabular}

Tabela 2 - Médias e desvios-padrão da força máxima de ruptura e do deslocamento do ligamento da cabeça do osso femoral, quando submetido ao ensaio mecânico destrutivo - Petrolina, 2010

\begin{tabular}{llllll}
\hline \multirow{2}{*}{ VARIÁVEL } & \multirow{2}{*}{ GÊNERO } & MÉDIA & & \multicolumn{2}{c}{ DESVIO PADRÃO } \\
\cline { 5 - 6 } & SEXUAL & $\begin{array}{l}\text { Antímero } \\
\text { direito }\end{array}$ & $\begin{array}{l}\text { Antímero } \\
\text { esquerdo }\end{array}$ & $\begin{array}{l}\text { Antímero } \\
\text { direito }\end{array}$ & $\begin{array}{l}\text { Antímero } \\
\text { esquerdo }\end{array}$ \\
\hline \multirow{2}{*}{ Força máxima de ruptura $(\mathrm{kg})$} & Fêmea & 22,00 & 21,18 & 8,55 & 8,45 \\
& Macho & 21,76 & 23,55 & 9,30 & 9,06 \\
\multirow{2}{*}{ Deslocamento $(\mathrm{mm})$} & Fêmea & 6,42 & 6,58 & 2,24 & 3,94 \\
& Macho & 6,31 & 7,76 & 4,22 & 3,73 \\
\hline
\end{tabular}

Primeiramente, notou-se não haver diferença significativa entre machos e fêmeas para ambos os antímeros. O mesmo pôde ser observado quando se comparava o ligamento da cabeça do osso femoral de um antímero com o seu contralateral, ou seja, suas resistências e deslocamentos não apresentavam diferenças significativas.

Quando foi considerado apenas o grupo formado por indivíduos do gênero feminino, foi possível notar, por meio do teste de correlação de
Pearson e da matriz de dispersão linear $(r>0,5)$, considerando-se as características corporais, força máxima de ruptura e deslocamento do ligamento da cabeça do osso femoral, que houve correlação significativa positiva entre a força máxima de ruptura do antímero direito e a força máxima de ruptura do antímero esquerdo.

Estudando os antímeros separadamente, observou-se que o deslocamento do antímero direito tem correlação significativamente positiva com a 
força máxima de ruptura, altura e massa corpóreas, sendo que essas últimas evidenciam que a estrutura de sustentação é diretamente proporcional. Já o antímero esquerdo apresenta correlação significativamente positiva com altura e comprimento corporais, corroborando com a afirmação anterior.

Ao isolar o grupo de indivíduos do gênero masculino, comprovou-se, por meio da análise estatística com matriz de dispersão e coeficiente de correlação de Pearson ( $r>0,5)$, considerando-se as características corporais, força máxima de ruptura e deslocamento do ligamento da cabeça do osso femoral, que:

- a força máxima de ruptura do antímero direito era diretamente proporcional à força máxima de ruptura do antímero contralateral;

- a força máxima de ruptura do antímero direito era diretamente proporcional à massa corpórea;

- a força máxima de ruptura do antímero esquerdo foi diretamente proporcional à altura, comprimento e massa corporais;

- o deslocamento do ligamento da cabeça do osso femoral do antímero direito foi diretamente proporcional ao comprimento, altura e massa corporais.Com base no que foi mencionado acima, notou-se que as estruturas de fixação e sustentação do esqueleto tendem a adequar-se conforme a exigência, ou seja, quanto maiores às dimensões corpóreas, maior era a resistência do ligamento em questão.

Considerando o princípio físico de arquitetura do organismo animal, sabe-se que o ligamento da cabeça do osso femoral comporta-se de maneira transversal ao esqueleto axial, promovendo o ancoramento da cabeça do osso femoral na fossa acetabular, colaborando na sustentação do organismo na porção terminal do terço caudal da coluna vertebral. Assim, foi possível notar que quanto maior era a altura do animal, maior a resistência do ligamento em questão - fato observado quando se agruparam os animais do sexo masculino com os do gênero feminino, utilizando matriz de dispersão e coeficiente de correlação de Pearson $(r>0,5)$, considerando-se as características corporais, força máxima de ruptura e deslocamento do ligamento da cabeça do osso femoral.

Durante a confecção do presente trabalho, observou-se que a quantidade de publicações acerca do assunto era incipiente, o que fez com que fossem transcritos trabalhos concernentes à anatomia da articulação coxal, bem como do ligamento da cabeça do osso femoral e relatos de animais displásicos.

Segundo LEMOS et al. (2007), existe uma série de afecções ortopédicas causadas pela combinação de fatores como hereditariedade, dieta alimentar, atividade física e manejo. A displasia coxofemural é o exemplo mais comumente encontrado clinicamente em cães, sendo um distúrbio degenerativo, progressivo e irreversível, constituindo grave problema, porque está associada à osteoartrite coxofemoral, mobilidade/amplitude limitada da articulação, dor e claudicação em graus variáveis. Em cães, é um processo doloroso porque o desgaste articular expõe as fibras álgicas no osso subcondral. A patologia manifesta-se por vários graus de instabilidade e má formação da cabeça do osso femoral e do acetábulo, bem como da frouxidão dos tecidos moles, a qual pôde ser calculada a partir da análise e determinação do deslocamento das garras do equipamento de ensaio mecânico destrutivo, que provoca ruptura no ligamento da cabeça do osso femoral, o que tornou possível verificar sua resistência.

PALASTANGA et al. (2000) observaram que a função do ligamento da cabeça do osso femoral é incerta nos seres humanos adultos. Já, FRANK (2004) acredita que esses ligamentos são tecidos conjuntivos especializados de interessantes funções biomecânicas, pois possuem fibras de constituição complexa que se comprimem e relaxam conforme movimentação de músculos e ossos. Em cães, foi possível determinar que tal relaxamento permite o afastamento da cabeça do osso femoral de sua respectiva fossa acetabular a uma distância máxima de $6,77 \mathrm{~mm}( \pm 3,53)$ até que haja sua ruptura. Isso comprova a importância desse ligamento em cães, sendo uma das estruturas responsáveis pela sustentação do membro pélvico.

De acordo com FRANK (2004), funcionalmente, dependendo da intensidade da aplicação e distribuição de forças sobre estruturas relacionadas aos ligamentos, poderá ocorrer uma mudança drástica em sua estrutura e fisiologia, instalando-se quadros de formação de tecido cicatricial que é biologica e biomecanicamente inferior ao tecido original. DENNIS et al. (2001), ao analisarem in vivo a separação da articulação do quadril sob forças geradas em condições de impacto, descreveram a importância do ligamento da cabeça do osso femoral, juntamente com a cápsula articular e a margem acetabular, na sustentação dessa articulação, pois promovem uma força passiva e resistente nessa estrutura, impedindo a separação entre o osso femoral e o acetábulo. Os resultados do presente trabalho corroboram os resultados encontrados por esses autores, pois forças opostas atuantes sobre o ligamento da cabeça do osso femoral podem não apenas gerar alterações na conformação durante a tração, mas também provocar sua ruptura, quando submetido à carga de $22,11 \mathrm{~kg}$ $( \pm 8,84)$, a qual aconteceria em situação de avulsão 
do membro pélvico, como em casos de acidentes de alto impacto, ou seja, a força deveria incidir do plano medial para o lateral.

Para CARPENTER \& HANKENSON (2004), é fundamental o estabelecimento de modelos animais para a avaliação do emprego de novas técnicas, sobretudo na busca por tecidos que mais se assemelhem aos do homem. FRANK et al. (2005) afirmam que essa busca reveste-se de fundamental importância, pois ainda permanecem dúvidas sobre a compreensão da estrutura dos ligamentos principalmente no tocante ao entendimento de sua determinação gênica, estrutural e funcional, sendo que, hoje, nas injúrias tendíneas e de ligamentos, tende-se ao emprego de técnicas avançadas, que incluem a utilização de novos materiais sintéticos, aplicação de moléculas bioativas e também procedimentos de transferências gênicas.

Segundo FONTANA (2006), várias são as citações na literatura sobre a utilização de cães e ovinos como excelentes representantes de modelos experimentais nas pesquisas ortopédicas, como no caso de estudos relacionados à análise e à colocação de próteses articulares coxofemurais em seres humanos. Existem, ainda, relatos de estudos implicados na reconstrução ou substituição de ligamentos, tratamentos de lesões costocondrais ou osteocondrais e na patogênese de osteoartroses. No entanto, para buscar-se tal tecido, deve-se primeiramente, ter conhecimento pormenorizado acerca do mesmo, como é o caso da resistência estabelecida pelo presente estudo.

Além do material sintético a ser desenvolvido, há de se elaborar técnicas que permitam restaurar a estabilidade original promovida pelo ligamento da cabeça do osso femoral (BRANDÃO et al., 2002). A reconstrução desse ligamento após a redução cirúrgica de luxação tem sido descrita utilizando-se principalmente materiais sintéticos, como fios de polietileno, náilon, poliéster, fio de aço e pino intramedular de Steinmann ou fio de Kirschner moldado. Com o conhecimento da resistência do ligamento da cabeça do osso femoral, obtido por meio deste estudo biométrico, o cirurgião poderá optar pelo material sintético que melhor venha a se adaptar ao procedimento de substituição. A aplicação da biometria e suas correlações com a resistência desse ligamento, em um modelo experimental, permitem o estabelecimento de parâmetros fundamentais nas análises comparativas, o que foi realizado neste trabalho.

DEMANGE et al. (2007), durante estudo realizado em humanos, investigaram influência do ligamento da cabeça do osso femoral no arco de movimento de flexão-extensão e de adução-abdução do quadril e concluíram que o ligamento da cabeça do osso femoral influi limitando a adução do quadril, o que também ocorre no caso dos cães, apresentando um limite máximo de afastamento entre a cabeça do osso femoral e da fossa do acetábulo.

O ligamento da cabeça do osso femoral dos cães comporta-se de maneira transversal ao esqueleto axial, promovendo o ancoramento da cabeça do osso femoral na fossa acetabular, colaborando com a sustentação do organismo na porção terminal do terço caudal da coluna vertebral. Destarte, proporciona estabilização da articulação coxal desses animais - observações que se assemelharam, em parte, às afirmações de DENNIS (2001), pois o presente trabalho realizou técnicas específicas relacionadas à resistência desses ligamentos, o que proporciona a comprovação de suas observações, as quais estimam a promoção de uma força passiva e resistente ao impedimento da separação do osso femoral de seu respectivo acetábulo.

SIA et al. (2009) estudaram a comparação entre a técnica de substituição do ligamento redondo por implantes de fáscia lata bubalina preservada em glicerina e o uso de pino transarticular na redução e na estabilização da luxação coxofemoral experimentalmente induzida em cães. Os autores notaram que não houve diferença significativa entre ambas as técnicas com relação à tensão empregada sobre o material aplicado, evidenciando que as estruturas articulares responsáveis pela sustentação do membro pélvico mostraram tensão similar aos materiais substitutos, sem, no entanto, estabelecer a tensão individualizada de cada estrutura articular. Já o objeto de estudo do presente trabalho - o ligamento da cabeça do osso femoral - foi pesquisado separadamente das demais estruturas articulares, elucidando os resultados em valores numéricos.

\section{CONCLUSÕES}

Num grupo considerável de animais $(33,33 \%)$, a resistência do ligamento da cabeça do osso femoral foi superior à do próprio osso que, durante o ensaio mecânico destrutivo, fraturou-se na altura do colo, em pelo menos um dos antímeros, antes mesmo da ruptura do ligamento em questão.

Ao comparar as análises estatísticas entre os antímeros, foi possível averiguar que a força máxima de ruptura era semelhante entre eles. Além disso, ficou evidente que o deslocamento máximo do ligamento da cabeça do osso femoral e a força máxima de ruptura eram proporcionais às dimensões e à massa corpórea dos indivíduos, ou seja, quanto maior o animal, maior a resistência do ligamento e maior o afastamento permitido entre a cabeça do osso femoral e sua respectiva fossa do acetábulo. 


\section{AGRADECIMENTOS}

Os pesquisadores agradecem ao Conselho Nacional de Desenvolvimento Científico e Tecnológico (CNPq) pelo apoio; ao Centro de Controle de Zoonoses do Município de Petrolina, pela concessão dos animais; e a todos que, direta ou indiretamente, contribuíram para realização do presente trabalho.

\section{REFERÊNCIAS}

BRANDÃO, C. V. S.; IAMAGUTI, P.; FIGUEIREDO, L. M. A.;. Substituição do ligamento da cabeça do fêmur com auto-enxerto de fáscia lata na luxação coxofemoral em cães. Ciência Rural, v. 32, no. 2, pp. 275-280, 2002.

CARPENTER, J. E.; HANKENSON, K. D. Animal models of tendon and ligament injuries for tissue engineering applications. Biomaterials, v. 25 , n. 9, p.1715-1722, 2004.

DEMANGE, M. K.; KAKUDA, C. M. S.; PEREIRA, C. A. M. ; SAKAKI, M. H.; ALBUQUERQUE, R. F. M. Influência do ligamento da cabeça do fêmur na mecânica do quadril. Acta Ortopédica Brasileira. V.15. n.4. p.187190, 2007.

DENNIS, D. A.; KOMISTEK, R. D.; NORTHCUT, E. J.; OCHOA, J. A.; RITCHIE, A. "In vivo" determination of hip joint separation and the forces generated due to impact loading conditions. Journal of Biomechanics, v. 34, n. 5 , p. 623-629, 2001.

DYCE, K. M.; SACK, W. O.; WENSING, C. J. G. Tratado de anatomia veterinária. 3 . ed. Rio de Janeiro: Elsevier, 2004. p. 456-458.

FARIA, M. D. Dimensões e massa dos órgãos internos de cães Pastores Alemães (Canis familiaris LINNAEUS, 1758). 245 f. Tese (Doutorado em Anatomia dos Animais Domésticos e Silvestres) - Faculdade de Medicina Veterinária e Zootecnia, Universidade de São Paulo, São Paulo, 2007. Disponível em: http://www.teses.usp.br/teses/disponiveis/10/10132/tde13122007-130403/pt-br.php. Acesso em 20/03/09.
FONTANA, C.A.P.; MACHADO, M.R.F.; PACHECO, M.R.; FONTANA, V.D.L.S.; SASAHARA, T.H.C. Morfologia do ligamento da cabeça do fêmur de ovinos da raça santa inês. Ars Veterinaria, Jaboticabal, SP, Vol. 23, n³, 158-164, 2007.

FRANK, C. B. Ligament structure, physiology and function. Journal Musculoskel Neuron Interact (Review Article), v. 4, n. 2, p. 199-201, 2004.

FRANK, C. B.; MARCHUK, L. L.; WOO, S. L. Y. Summary and future directions (review article). Sports Medicine Arthroscopy Review, v.13, n.3, p.177-183, 2005.

HIBBELER, R.C. Resistência dos Materiais. PrenticeHall, ed.5,p.01, 2004.

INTERNATIONAL COMMITTEE ON VETERINARY GROSS ANATOMICAL NOMENCLATURE; GENERAL ASSEMBLY OF THE WORLD ASSOCIATION OF VETERINARY ANATOMISTS. Nomina Anatomica veterinaria. 5. ed. Hannover: W.A.V.A., 2005, p. 117-180.

LEMOS, C. M.; FISCHER, C. D. B.; PINTO, V. M.; MAIA, J. Z.; BUENO, P. L. G.; MARCONATO, F.; BOARO, E.; ROSA, P.; BAJA, K. G. Prevalência da displasia coxofemoral em cães atendidos no Hospital Veterinário da Universidade Luterana do Brasil no setor de Reabilitação Animal.CONBRAVET, CanoasRS. 2007, Anais..., disponível em http://www.sovergs.com.br/conbravet2008/anais/cd/resum os/R0688-3.pdf, acesso em julho de 2012.

PALASTANGA, N.; FIELD, D.; SOAMES, R. Anatomia e movimento humano: estrutura e função. 3. ed. São Paulo: Manole, 2000. p. 353-376.

SAS. V.9 1. 3. SAS Institute Inc., Cary, NC, USA. $2002-$ 2003.

SIA, D. B.; GOMES, C.; CONTESINI, E. A.; BOTH, A. C.; SOUZA, E. M.; FERREIRA, M. P.; GOMES, H. M.; COLOMÉ, L. M.; FERREIRA, R. R. Comparação entre a técnica de substituição do ligamento redondo por implante de fascia lata bubalina preservada em glicerina e o uso de pino transarticular na redução e na estabilização da luxação coxofemoral experimentalmente induzida em cães. Arquivo Brasileiro de Medicina Veterinária e Zootecnia, v. 61, n. 4, p. 825-834, 2009. 